\title{
El pluralismo cultural y la gestión política de la inmigración en Chile: ¿ausencia de un modelo?
}

\author{
Liván Usallán Méndez \\ Universidad Diego Portales, Santiago, Chile. \\ Email: livan.usallan@gmail.com
}

\begin{abstract}
Resumen $^{1}$ : En el presente trabajo realizamos un análisis sobre las principales características del paradigma del asimilacionismo y del paradigma del pluralismo cultural desde una perspectiva de gestión de la diversidad en sociedades multiculturales. Establecemos las diferencias teóricas entre ambas paradigmas, así como los modelos de gestión que emanan de los mismos. Seguidamente nos centramos en el examen del marco normativo desarrollado por el Estado chileno en materia de migración para determinar el paradigma de gestión predominante en dicho marco.

Palabras clave: Pluralismo cultural, asimilacionismo, modelos de gestión, política migratoria, Chile.
\end{abstract}

\section{The cultural pluralism and the immigration political management in Chile: $\dot{c}$ absence of a model?}

Abstract: The aim of this paper is to analyze the main features of the assimilationist and cultural pluralism paradigm from the perspective of managing diversity in multicultural societies. We will stand out theoretical differences between the two paradigms and the management models which arise from them. Then we will focus on Chilean State legal framework regarding migration, to determine what management paradigms prevail in it.

Keywords: Cultural pluralism, assimilationism, management models, immigration policies, Chili.

\section{Pluralismo cultural e gestão política de imigração no Chile: ausência de um modelo?}

Resumo: Neste trabalho, analisamos as principais características do paradigma assimilacionista e do paradigma do pluralismo cultural a partir da perspectiva da gestão da diversidade nas sociedades multiculturais. Estabelecemos as diferenças teóricas entre os dois paradigmas, assim como os modelos de gestão que emanam deles. Seguidamente centramonos na análise do quadro normativo desenvolvido pelo Estado chileno em matéria de migração para determinar o paradigma de gestão dominante nesse âmbito.

Palavras-chave:pluralismo cultural, assimilacionismo, modelos de gestão, política de imigração, Chile. 


\section{Introducción}

No cabe duda de que los flujos migratorios internacionales constituyen uno de los fenómenos sociales de mayor relevancia a la hora de examinar la complejidad de nuestras sociedades actuales; también a la hora de delinear una perspectiva de la sociedad futura. En efecto, las migraciones internacionales han hecho saltar por los aires, o al menos estremecido, la relativa tranquilidad con la que solían pensarse un conjunto de categorías políticas que parecían avanzar hacía su madurez desde su surgimiento moderno.

El presente texto pretende realizar una reflexión general sobre el marco institucional y político de la convivencia en una sociedad culturalmente diversa y sobre los retos de profundización democrática para gestionar, en términos de igualdad, la importante presencia de población migrante. Todo ello con la pretensión de indagar en el caso chileno y de evaluar las respuestas que el Estado está dando al flujo de las migraciones internacionales.

Para ello se abordarán dos grandes ámbitos igualmente centrales para el debate propuesto: los paradigmas de gestión de la diversidad cultural y la respuesta del Estado chileno con respecto al fenómeno de las migraciones internacionales y su creciente multiculturalidad interna.

Un primer apartado del trabajo que presentamos estará dedicado a preguntarnos sobre qué entender por gestión de la diversidad cultural. Lo haremos a partir del análisis de los paradigmas y modelos que históricamente han marcado e inspirado las políticas sobre la multiculturalidad. Además, revisaremos la interacción entre los conceptos de ciudadanía, derechos y democracia.

Un segundo apartado indagará en el marco normativo vigente del Estado chileno en materia de migración para determinar el paradigma de gestión predominante. También se abordará si la firma por parte del Estado de numerosos instrumentos internacionales referidos al fenómeno migratorio se ha traducido en políticas estatales al respecto.

Finalmente, analizaremos el estado actual de las políticas de gestión de la diversidad cultural en Chile en relación con los paradigmas estudiados. Consideramos que a partir de lo anterior podremos entregar un panorama adecuado del espíritu normativo que prima en las respuestas del Estado chileno relacionadas con la gestión política de las migraciones internacionales.

\section{Paradigmas y modelos de la gestión de la diversidad cultural}

El fenómeno migratorio es uno de los que mejor permite evidenciar el carácter excluyente y reduccionista del status de ciudadanía nacional, así como el anquilosamiento de la democracia formal y de la materialización 
política y jurídica con respecto al extranjero. Como acertadamente señala De Lucas (2009: 12), las modernas migraciones tienen todos los rasgos del proceso de globalización, en este sentido, son difícilmente abarcables desde una perspectiva estatal nacional que sigue siendo hoy la dominante en el mundo jurídico.

Por sí solo el enunciado gestión de la diversidad cultural no posee una orientación jurídico-política definida. Son los modelos que se articulan para dar respuesta al fenómeno de la diversidad cultural los que dotan a la gestión de una concepción u otra sobre cómo, por qué y para qué gestionar. De esta manera podemos encontrar un conjunto de modelos, más o menos elaborados, que conforman el devenir histórico del tratamiento de las diferencias culturales en el seno del Estado-nación.

Es precisamente la identidad colectiva que el Estado-nación fijara desde su formación, como expresión de la cultura mayoritaria, la que nutre una cultura político-jurídica que define un nosotros frente a los otros. Se convierte así dicha cultura identitaria en una dinámica de inclusión-exclusión que abarca todos los aspectos de la vida social y política, articulada por el concepto de ciudadanía y el principio de la identidad, entendida como identidad nacional.

Es necesario establecer claridad entre paradigmas y modelos dentro de este escenario en cuestión. Lo que entendemos por paradigma es una cosmovisión que, en tanto conjunto de creencias y valores, afectan la forma en que un individuo percibe la realidad. Lo anterior deriva de la conocida noción de paradigma científico creada y desarrollada por Thomas Khun (1971). Así, los paradigmas científicos son realizaciones científicas universalmente reconocidas que, durante cierto tiempo, proporcionan modelos de problemas y soluciones a una comunidad científica (Kuhn, 1971: 13). En la lógica de Kuhn, un paradigma puede estar compuesto por dos o más teorías en dependencia de la amplitud del paradigma (Ritzer, 1993: 596). Por ello asumimos las teorías, relativas a la gestión de la diversidad cultural, como modelos que articulan diferentes visiones de un objeto.

\section{El asimilacionismo: desde la cultura monolítica a la fusión cultural}

El asimilacionismo, como paradigma de gestión de la diversidad, asume que el otro cultural tiene que adaptarse al estereotipo mayoritario prescindiendo de su marco cultural vital. Esta adaptación, independientemente de sus matices, se produce de manera unilateral. Así, el asimilacionismo comprende al otro como aquél que debe transitar a través de un proceso en el que adopta como propia la cultura dominante en la sociedad. Se legitima así la idea de que los inmigrantes se incorporen a sociedades crecientemente constituidas sobre la base de una cultura hegemónica y que identifica cohesión y homogeneidad (Torres, 2005: 62). 
La relación entre Estado y cultura queda sacralizada desde el momento en que todo individuo que requiera el consentimiento y el respaldo del Estado para su actuar en la esfera pública deberá asumir como propios los códigos de la cultura dominante. Aunque podamos asumir la ciudadanía como un estatuto formal de pertenencia a una comunidad política, se trata de una categoría multidimensional que constituye, de forma paralela, un concepto jurídico, un ideal político igualitario y una referencia moral en la que se recogen los derechos, las obligaciones y las lealtades de los individuos hacia una comunidad política dada (Colom, 1998: 235).

Es el Estado, a fin de cuentas, quien establece, en función de normas establecidas, cuándo se adquiere y se pierde el estatuto de ciudadanía. En el diseño de esas normas juegan un papel determinante la esencialidad cultural que se le imprima a la nación o la esencialidad nacional que se le adjudique a la cultura.

Cuando se habla del proceso de asimilación no cabe pensar, necesariamente, en medidas de coerción explícitas. Aunque éstas no han faltado, el éxito del proceso de asimilación se basa en las dinámicas sociales y la acción de las instituciones, con sus exigencias de adaptación a las costumbres. Todo ello resulta contradictorio con el origen esencialmente democrático y universalista, como concepción política, de la ciudadanía. Con su institucionalización se privilegió la particularidad y, a través del patriotismo, la transformación de la abnegación individual en egoísmo colectivo (Colom, 1998: 236).

El proceso de asimilación adoptó unas formas u otras según la distinta tradición política e identitaria de cada país; las diferentes formas con que interrelacionaban el Estado, la cultura mayoritaria y las minorías; y el tipo de cohesión social perseguida por cada contexto histórico. Dentro de esta concepción destacan dos modelos: anglo-conformity y melting pot.

El modelo anglo-conformity, también conocido como americanización, constituyó la expresión de la ideología dominante hacia la inmigración en la historia de los Estados Unidos hasta mediados del siglo $\mathrm{XX}^{2}$. Sus inicios guardan relación con la preocupación de los padres fundadores con respecto a las oleadas migratorias, que podrían ser una amenaza para las jóvenes instituciones americanas fundamentadas en la democracia y el republicanismo (Bajo, 2007: 820).

En este sentido, las masas de inmigrantes, principalmente europeos, podrían irrumpir desestructurando los valores democráticos de la nueva nación. Los recién llegados eran vistos como potenciales portadores de relaciones sociales que respondían a dinámicas inherentes a monarquías despóticas. Además, para los fundadores representaría un problema que los inmigrantes quisieran mantener sus lenguas y sus costumbres.

De este modo, Bajo (2007) reproduce el criterio que sobre los inmigrantes, específicamente los europeos, expusiera en un intercambio epistolar el secretario de Estado John Quincy Adams en 1818: 
...they must make up their minds, or they will be disappointed in every expectations of happiness as Americans. They must cast off the European skin, never to resume it. They must look forward to their posterity rather than backward to their ancestors; they must be sure that whatever their own feelings may be, those of their children will cling to the prejudices of this country (Bajo, 2007: 820).

Lo anterior refleja de manera explícita la americanización de los inmigrantes que el anglo-conformity supone. No obstante, de manera implícita se parte de la percepción, casi canónica, de que la sociedad de acogida es culturalmente monolítica. Ello es reflejo, en este caso concreto, de que la nación se proyecta desde el Estado dejando en sus márgenes la diversidad cultural preexistente a su diseño y la imposición de una cultura con jerarquía nacional.

El melting pot, también conocido como fusión cultural o amalgamación, se inserta dentro del paradigma asimilacionista, aunque con variaciones respecto a la forma en la que se persigue la homogenización cultural en una sociedad determinada ${ }^{3}$. El término melting pot aparece por primera vez en 1908 en la obra dramática del escritor estadounidense Israel Zangwill, The Melting Pot, en la que se dibuja una imagen de Estados Unidos como el crisol de Dios.

El núcleo argumental de la fusión cultural se encuentra en la idea de que la cultura nacional o la identidad cultural de un determinado país debe configurarse a partir de las contribuciones de todos los sectores en él representados o incorporados (Malgesini y Giménez, 2000: 201), lo que apunta a la homogenización como punto de llegada y no como punto de partida. Ello buscaba producir una legitimidad histórica al presentar a los Estados Unidos como esa tierra en la que prevalecían los valores democráticos y el ambiente social por encima de la "raza" y la cultura.

Para (Herver, 1964), lo que se ha producido en Estados Unidos es un triple melting pot que incluye a la "América" católica, la protestante y la judía, mientras que los colectivos asiáticos e hispanos no se han fusionado significativamente, lo que revela la insistencia del rol de la etnicidad, al mismo tiempo que nos recuerda no perder de vista que las dinámicas de agrupamiento poseen una dimensión de naturaleza religiosa o cultural.

\section{El pluralismo cultural: entre el multiculturalismo y el interculturalismo}

El debate sobre el pluralismo cultural ha producido una amplia bibliografía desde los años sesenta del siglo pasado. Es en el contexto europeo y estadounidense donde se comienzan a perfilar de forma definitiva los elementos principales de este paradigma. Decimos de forma definitiva, pues 
las primeras referencias sobre el pluralismo cultural pueden ser ubicadas desde principios del siglo XX.

El filósofo Horece Kallen apunta el término de cultural pluralism en un artículo de 1919 publicado por el diario estadounidense The Nation. En el mismo Kallen hacía referencia a que América no podía concebirse como un melting pot sino como una cooperación de diversas culturas o como una federación de culturas nacionales en el marco de una unidad político administrativa (Bajo, 2007: 825).

Como principio liberal, el pluralismo se nos presenta como una de las consecuencias de la autonomía del individuo, esto es, la libertad de elegir y expresar en el espacio público la identidad individual. El problema aparece cundo determinadas expresiones no son coherentes con la identidad nacional fijada y favorecida por el Estado. Aquí entraríamos no solamente en la necesidad del reconocimiento de la diferencia, sino que también saldría a relucir el debate sobre si existe una jerarquía de valores.

Con ello se introduce otro tema de discusión que intenta reducir o etiquetar las propuestas del pluralismo cultural como un relativismo cultural. Según Pérez de la Fuente (2005: 391), la polémica sobre el valor igual de las culturas presenta argumentos multidireccionales en distintos niveles del debate. Por ello insiste en que para avanzar en este tema sería necesario distinguir entre un punto de vista cultural y un punto de vista moral a la hora de establecer valoración y comparaciones entre culturas. De esta manera nos evitaríamos confundir al relativista moral con el relativista cultural.

Si bien consideramos el pluralismo cultural como un paradigma en tanto cosmovisión que interpreta la diversidad cultural como un escenario potencialmente enriquecedor para la vida en sociedad, sería necesario destacar que su etimología está constituida por una dimensión descriptiva sobre la cual se intenta reflexionar.

\section{Como señala Giménez:}

'Pluralismo cultural' connota, en primer lugar, la presencia, coexistencia o simultaneidad de poblaciones con distintas culturas en un determinado ámbito o espacio territorial y social, sea un área civilizatoria, una entidad supranacional, un Estado nación, una nación sin Estado, una región, un municipio, una comunidad local, o una escuela. Pero por 'pluralismo cultural' también se entiende una determinada concepción de la diversidad cultural y una determinada propuesta sobre la forma legislativa, institucional, etc., en que debería abordarse en la práctica (2003: 16).

En este sentido, los ejes del pluralismo cultural estribarían en el principio de igualdad con especial énfasis en la no discriminación en función de la cultura, etnia, religión, lengua, nacionalidad, origen regional y la comprensión de la diferencia a través del respeto y la aceptación del otro. A 
partir de estos presupuestos podemos identificar dos modelos que han sido construidos bajo la égida del pluralismo cultural: multiculturalismo e interculturalismo.

El multiculturalismo se concibe, por un lado, como hecho social (dimensión descriptiva). Se entiende como la convivencia en un mismo espacio social de personas identificadas con culturas de naturaleza variada. Por otro lado, se entiende como un proyecto político e ideológico (dimensión normativa). Insiste en el respeto de las identidades culturales en una mutua convivencia representada en el espacio público y político (Lamo y Llobera, 1995: 18). Esta dimensión normativa excluye al llamado multiculturalismo radical que niega el intercambio entre grupos culturales como especies de culturas incontaminadas.

Las principales elaboraciones sobre el multiculturalismo como propuesta de gestión de la diversidad cultural provienen de los años sesenta del siglo pasado, y toman como referencia las nociones fundamentales del pluralismo cultural. Canadá se ha convertido, en términos jurídicos primero y en sentido práctico después, en un contexto de referencia imprescindible para visualizar la positivización jurídica de este modelo.

Frente al principio de igualdad de todos los ciudadanos ante la ley y los derechos fundamentales, se nos presenta la cuestión de la imposibilidad de que los ciudadanos de un Estado pertenecientes a las minorías, puedan disfrutar de su contexto cultural específico como referencia fundamental para expresar sus necesidades religiosas, lingüísticas y políticas. De ahí que la perspectiva multiculturalista concibe a la sociedad política como un espacio integrado por una pluralidad de comunidades culturales estables y viables, que han de ser consideradas de igual rango, sin que pueda presumirse que la sociedad pertenece más a ninguna de ellas que a otra (Peña, 2000: 64).

Se podrían resumir sus principales características de la forma siguiente:

- El multiculturalismo es un proyecto filosófico-político que destaca el rol de la cultura como contexto de referencia imprescindible, desde donde individuos y colectivos efectúan procesos de significación que deben ser integrados en el espacio público. Por ello la reflexión que realiza abarca los campos legal, identitario y moral, como espacios interrelacionados y complementarios.

- El reconocimiento de contextos referenciales particulares es vital para la convivencia mutua a partir de procesos deliberativos y no a través de la homogenización cultural bajo el patrón de la mayoría.

- Este proyecto posee un alto nivel descriptivo, algo valioso dentro de la teoría social, pues lo provee de una orientación normativa en diálogo con la realidad que se describe. Reduce los niveles de desfasaje entre la norma y su objeto ${ }^{4}$. 
- Implica una restructuración profunda del concepto de ciudadanía entendida como estatus. La igualdad de derechos no es suficiente si el individuo está limitado en su expresión identitaria dentro de la comunidad política, ya sea a nivel representativo o participativo.

El interculturalismo va más allá de los derechos y deberes de reconocimiento del multiculturalismo, pero sin prescindir de ellos. Como señala Etxeberria (2004: 51), esto se debe a que el interculturalismo supone el aprecio a la diversidad cultural como expresión pluriforme de una unidad común, y a la consideración de que todas las culturas tienen valores y capacidades creativas con las que es positivo entrar en contacto.

Se podría diferenciar el multiculturalismo del interculturalismo comprendiendo al primero como el respeto coherente y eficaz por parte de un Estado hacia las prácticas tradicionales. Por ejemplo, el uso de orden jurídico propio de grupos culturales junto al del Estado ligado a la tradición del Derecho romano. Mientras que el interculturalismo fomentaría un diálogo equitativo entre esos sistemas con vistas a la crítica y a la apertura a su evolución sin perder la pluralidad (Etxeberria, 2004: 52).

Sin embargo, no queda del todo clara esta distinción. Si de lo que se trata esque en el multiculturalismo convivan órdenes jurídicos distintos (el de la minoría y el del Estado) y en el interculturalismo estos órdenes dialoguen equitativamente evolucionando hacia una cooperación que no asimile, estaríamos en presencia de una comprensión reducida del multiculturalismo ${ }^{5}$.

La equidad de diálogo que el interculturalismo propone parece de difícil ejecución sin una base jurídico-política que reconozca y posibilite la participación de las minorías en la toma de decisiones comenzando por su propio contexto local. Cualquier proceso de diálogo es asimétrico, por lo que se trata de crear mecanismos, más que voluntades, que reduzcan las posibilidades de que las asimetrías sean utilizadas como dominación a través de la imposición de posturas.

Usualmente se ha presentado la universalidad de los derechos fundamentales como un tema de consenso, es decir, que el hecho de su universalidad significa acuerdo compartido por todos sus defensores. Uno de los problemas con el interculturalismo, pero también con el multiculturalismo, es la sugerencia de que ante la diversidad se mantenga la inviolabilidad de esos derechos.

Ferrajoli (2007: 57) plantea que en este debate existe una sustancial confusión conceptual. Es habitual que los diferencialistas asuman el universalismo de los derechos fundamentales como una manifestación de la dominación de la cultura occidental en su intento por imponer sus nociones de igualdad y libertad. Por parte de los universalistas se sostiene que estos valores deberían ser compartidos por todos. Pero si este fuera el significado del universalismo, lo primero que se debería señalar es que: 
...desde la libertad de conciencia, a las demás libertades fundamentales, desde la igualdad de las personas hasta los derechos sociales, no son de hecho compartidos por todos: no solamente no lo son por gran parte de las personas que tiene una cultura distinta de la occidental, sino ni siquiera por parte de las personas que han nacido y pertenecen a nuestra cultura (Ferrajoli, 2007: 58).

Con ello se deconstruye el argumento de que el universalismo de los derechos humanos deba entenderse como una noción natural. No se trata de una descripción de lo que la realidad es, más bien es una prescripción que contempla la correlación siempre existente entre normas y hechos.

El interculturalismo se nos presenta como una propuesta ética que proyecta el diálogo intercultural como elemento sustantivo de la convivencia en un contexto de diversidad. Sus campos de acción se centran en el tema de la identidad y la cultura haciendo énfasis en la construcción dialogada de un marco de convivencia que no implique la asimilación a la cultura mayoritaria, ni el cierre cultural con el fin de mantener un esencialismo. Igualmente, plantea la necesidad de reconocer en los otros diversos valores que enriquezcan de manera mutua cada horizonte comprensivo.

\section{Ciudadanía, derechos y democracia}

Viene siendo habitual que la creciente diversidad cultural de nuestras sociedades se representa, ya sea a través de los medios de comunicación o de la economía de las políticas del discurso sobre la inmigración ${ }^{6}$, como un problema de alto potencial conflictivo que pone en constante peligro la "estabilidad social”. En apariencia este fenómeno nos estaría conduciendo a una inminente desintegración social, acompañada de una relativización y del deterioro de los valores democráticos.

Este panorama nos obliga a repensar la relación entre multiculturalidad y democracia. Vale la pena, aunque sea a modo puntual, recordar el espíritu de la mayoría de los discursos políticos de la modernidad concernientes a los vínculos de pertenencia a la comunidad política. Como principio, aquélla sustentaba la idea de que no deberían existir otros límites para la inclusión en la comunidad política que la disposición voluntaria de los individuos a participar de la conformación de la misma, con la consiguiente aceptación del pacto social realizado a través de procedimientos legítimos. Visto así, la comunidad política quedaría concebida como una comunidad abierta, por lo menos desde la teorización de la ciudadanía como un derecho categórico.

Sin embargo, en su aplicación este derecho se ve contradicho por un conjunto de exclusiones (derecho contingente como universal concreto) de diversa índole: etarias, étnicas, de género, nacionalidad, etc., que irán limitando la representación efectiva de la diversidad en el espacio público. Esta contingencia quedó paulatinamente establecida desde la lógica de la cultura mayoritaria o dominante. 
Es cierto que extrapolar el espíritu político del siglo XVIII a los inicios del siglo XXI no resulta del todo adecuado. Pero ello no impide reflexionar sobre los mecanismos de inclusión a la comunidad política de individuos culturalmente diversos a través de un proceso de deconstrucción que nos permita reelaborar conceptos políticos tales como democracia y ciudadanía.

La igualdad como principio categórico puede ser asumida como una norma que oriente la inclusión de individuos culturalmente diversos en el espacio público. Puede, además, ayudarnos a superar una concepción de ciudadanía identitaria que monopoliza la titularidad de derechos de representación en el espacio público y que excluye a aquéllos que no son parte del conjunto cultural mayoritario a cuya imagen y semejanza se diseña el espacio público. Cada vez es más evidente, al menos desde un punto de vista analítico, que lo que está en crisis es nuestra democracia, que no está sabiendo renovarse y acomodarse a los nuevos tiempos de diversidad cultural.

En el sentido anteriormente expuesto se hace inevitable manejar un concepto dinámico de ciudadanía, o un concepto de mínimos que facilite la interacción con la multiculturalidad. Asumimos la ciudadanía como un conjunto de concepciones histórico-políticas más que como un concepto definido. Utilizamos la noción de ciudadanía propuesta por Zapata Barrero (2001), pues nos brinda un núcleo conceptual que servirá de orientación para nuestro propósito.

En este sentido, ciudadanía se refiere a la “posición que una persona alcanza por adscripción o por consecución con el consentimiento y el respaldo del Estado, para actuar en la esfera pública” (Zapata Barrero, 2001: 7). Podemos apreciar que la misma hace referencia a una cualidad que una persona posee para actuar en el espacio público. Esta concepción de la ciudadanía deja entrever que la posibilidad de exclusión está presente en tanto que nuestra participación legítima en el espacio público está mediada por el consentimiento del Estado.

Zapata Barrero tiene razón al afirmar que "la ciudadanía ha sido históricamente una noción excluyente” (2001: 8-9). Constituye un límite, una distinción para diferenciar a aquéllos que pertenecen o no a la comunidad política. Principalmente si percibimos cómo el concepto moderno de ciudadanía comienza a disociarse de una exclusiva dimensión cultural para identificarse con una comunidad nacional jurídica y políticamente estructurada. En todo caso, la ciudadanía es bastante más que un mero instrumento formal. Se trata de una institución que, sobre todo a lo largo de la historia moderna y contemporánea, ha estado estrechamente vinculada al significado de esa vaporosa categoría política llamada 'identidad nacional’ (Velazco, 2006: 2).

Así, en los procesos de construcción de los Estados-nación la ciudadanía queda paulatinamente subsumida dentro de la identidad mayoritaria del Estado. Con ello se produce su jerarquización en tanto que los miem- 
bros de minorías nacionales, culturales, religiosas y lingüísticas pasan a ser ciudadanos de segundo orden cuyo camino para disfrutar de los derechos y deberes de la ciudadanía será el de la asimilación cultural. De modo que, "en los Estados donde se impuso el concepto de nación política fundamentado en la voluntad de los ciudadanos de pertenencia a su comunidad, las minorías internas sufrirían con el tiempo el intento de asimilación a la cultura dominante” (Ruiz Vieytez, 2006: 61). La experiencia demuestra que cuanto mayor y más exigente sea el componente identitario de la ciudadanía, menor será su capacidad de inclusión.

Ante este dilema las democracias deben asumir que los derechos, principalmente los civiles, sociales y políticos, no pueden quedar agotados en el concepto de ciudadano, en tanto termino omniabarcador que pretende adjetivar un conjunto de derechos. Ello ha sido producto del predomino de una lógica positivista que tiende a reducir el sentido de todo sustantivo a una adjetivación puntual.

De lo que se trata, cuando contrastamos los derechos humanos con el término de ciudadanía, es que a través de un reconocimiento real de los mismos se desborden los límites que históricamente ha supuesto la condición de ciudadano para el ejercicio de todo individuo, sea ciudadano o no, de los derechos humanos. Es de este modo como asumimos que en ningún caso los límites de la ciudadanía pueden privar a individuos, que no son considerados parte de la comunidad política, de un ejercicio pleno de los derechos humanos sea cual sea su marco de referencia cultural. Esto es lo que asumimos como una inclusión plena.

En consecuencia, consideramos indispensable otorgarle un rol preponderante al Derecho Internacional de los Derechos Humanos a la hora de analizar la relación entre multiculturalidad y democracia. Es en esta coyuntura donde dicha relación no debe quedar desestimada evitando concluir con suma ligereza que la democracia es ya un proceso acabado, principalmente, en cuanto a diversidad cultural se refiere.

\section{El estado actual de las políticas de gestión sobre migración extranjera en Chile}

\section{Contextualización de la inmigración en Chile.}

Se puede constatar, a través de diversos análisis sociológicos (Stefoni, 2011a), que Chile se encuentra dentro de los primeros países de América del Sur en cuanto a recepción de población inmigrante de origen extranjero. Durante las últimas dos décadas, en gran medida debido al efecto llamada del crecimiento sostenido de la economía chilena dentro de la región, así como por la estabilidad política, el crecimiento de los extranjeros residentes en Chile ha aumentado de forma significativa. Así lo muestran los datos del censo de 2002, el cual arrojó una población de 184.464 extran- 
jeros en el país. Ello significaba un claro incremento de este segmento poblacional con la recogida en el censo de 1992 en el cual se contabilizaron 114.597 personas de origen extranjero.

El censo de 2012 da cuenta de una población de 339.536 personas residentes en Chile nacidas en el extranjero. Este dato confirma lo cercano de las estimaciones realizadas por el Departamento de Extranjería y Migraciones del Gobierno de Chile, el cual a partir de los resultados del censo de 2002 y los permisos de residencias otorgados hasta diciembre 2009 preveía una población de 352.344 extranjeros residentes.

Pero algo que se escapa con gran facilidad, tanto de los censos como de las estimaciones gubernamentales, es cuantificar la población inmigrante en condiciones de irregularidad. No obstante, si tomamos en cuenta los datos de las solicitudes de regularización presentadas durante los dos procesos de amnistía migratoria, 1998 (23.000 solicitudes) y 2007 (50.705), podemos intuir con facilidad que el número inmigrantes en condición irregular puede llegar a ser significativa.

Como generalmente sucede, la reacción académica y social al fenómeno migratorio lleva una considerable ventaja con respecto a las reacciones políticas y jurídicas. Es así como desde comienzos de la primera década del presente siglo numerosas investigaciones comienzan a poner su acento en el análisis de la nueva realidad social chilena como sociedad receptora de migración (Cano y Soffia, 2009).

Las principales problemáticas objeto de análisis han sido las relacionadas con los procesos de integración (Jiménez y Huatay, 2005), de exclusión social en el mercado laboral chileno (Depolo y Henríquez, 2006) y de segregación residencial (Schiappacasse, 2008). Pareciese haber un consenso, a nivel de estos estudios, de que el tratamiento del fenómeno migratorio debe asumir una política pluralista orientada a facilitar el proceso de inclusión social y económica de la población extranjera residente en Chile.

Por otra parte, las reacciones políticas y jurídicas no han evolucionado en el sentido anteriormente mencionado. Como apunta Stefoni (2011b: 81):

... los programas e iniciativas impulsados por los distintos gobiernos democráticos buscaron solucionar los problemas que genera una ley anquilosada, restrictiva y lejos de las premisas de Derechos Humanos que debieran inspirarla, sin embargo, estas iniciativas no significan la eliminación de la normativa que genera estos problemas.

Se refiere a la Ley de Migración dictada en 1975 bajo la dictadura militar de Augusto Pinochet, que a día de hoy constituye la principal norma jurídica sobre extranjería vigente en el país. A ello se suma la inexistencia de una política migratoria intersectorial, pues en la materia han primado los criterios de "organización” administrativa y de control emanados del Mi- 
nisterio del Interior como máximo responsable de lo que hasta hoy puede llamarse, solo en términos retóricos, política de inmigración del Estado chileno. De hecho, ha prevalecido un enfoque de control de fronteras y de visualizar el fenómeno migratorio en términos de inmigrante =trabajador.

Desde un punto de vista de evolución histórica Chile ha asumido y reproducido una imagen de homogeneidad cultural de la comunidad política. Esta se ha construido fundamentalmente desde el poder estatal invisibilizando la diversidad existente mediante la utilización de distintos grados de consenso y violencia. Es precisamente desde esta matriz unificadora que la concepción sobre el otro se consolidó, elaborando, mediante su cierre, mecanismos de exclusión e invisibilización de todo aquello que no encajaba en el proyecto de nación unitaria.

Hecha esta descripción, a continuación analizaremos la concepción relativa a los derechos fundamentales en la normativa vigente en materia de migración. Para ello tomaremos en cuenta la perspectiva que sobre tales derechos ha desarrollado el pensador italiano Luigi Ferrajoli (2004), quien insiste en la idea de que los derechos fundamentales, expresados en la mayoría de las constituciones contemporáneas como titularidad de las personas, pueden ser considerados como derechos de papel, ya sea por la ausencia de un cuerpo coherente garantista para su ejercicio o por la instrumentalización excluyente de los no ciudadanos.

Ferrajoli también señala la confusión conceptual operada por el concepto derechos de ciudadanía propuesto por Thomas Marshall en su célebre e influyente ensayo de 1950 Ciudadanía y clase social. La crítica consiste en el carácter aglutinador de derechos (políticos, civiles y sociales) que Marshall transfiere al concepto de ciudadanía, olvidando que los derechos sociales y civiles nacen históricamente como derechos de la persona.

\section{La legislación vigente en materia de migración y derechos fundamenta- les. Su coherencia con el espíritu internacional}

El primer elemento que tenemos que identificar es la expresión constitucional del Estado chileno relativa a derechos fundamentales de la persona para visualizar en qué medida la categoría de ciudadano y la de extranjero constituye, en el caso de la primera, un monopolio de los derechos de la persona, y, en el caso de la segunda, la exclusión de derechos de la persona. La Constitución Política de la República de 1980, dictada por un régimen autoritario, se refiere a estos elementos de la siguiente manera:

\section{Capítulo I}

Bases de la institucionalidad

Artículo $1^{\circ}$.- Las personas nacen libres e iguales en dignidad y derechos.

El Estado está al servicio de la persona humana y su finalidad es promover el bien común, para lo cual debe contribuir a crear las condiciones sociales que permitan a todos y a cada uno de los inte- 
grantes de la comunidad nacional su mayor realización espiritual y material posible, con pleno respeto a los derechos y garantías que esta Constitución establece.

Artículo $5^{\circ}$

El ejercicio de la soberanía reconoce único como limitación el respeto a los derechos esenciales que emanan de la naturaleza humana. Es deber de los órganos del Estado respetar y promover tales derechos, garantizados por esta Constitución, así como por los tratados Internacionales ratificados por Chile y que se encuentren vigentes.

Capítulo II

Nacionalidad y Ciudadanía

Artículo 10.

Son chilenos:

$1^{\circ}$. Los nacidos en el territorio de Chile, con excepción de los hijos de extranjeros que se encuentren en Chile en servicio de su Gobierno, y de los hijos de extranjeros transeúntes, todos los que, sin embargo, podrán optar por la nacionalidad chilena.

$2^{\circ}$. Los hijos de padre o madre chilenos, nacidos y en territorio extranjero. Con todo, se requerirá que alguno de sus ascendientes en línea recta de primer o segundo grado, haya adquirido la nacionalidad chilena en virtud de lo establecido en los números $1^{\circ}, 3^{\circ}$ ó $4^{\circ}$; $3^{\circ}$.- Los extranjeros que obtuvieren carta de nacionalización en conformidad a la ley.

$4^{\circ}$. Los que obtuvieren letra especial gracia de nacionalización por ley.

La ley reglamentará los procedimientos de opción por la nacionalidad chilena; de otorgamiento, negativa y cancelación de las cartas de nacionalización, y la formación de un registro de todos estos actos.

Artículo 14

Los extranjeros avecindados en Chile por más de cinco años, y que cumplan con los requisitos señalados en el inciso primero del artículo 13, podrán ejercer el derecho de sufragio en los casos y formas que determine la ley.

Los nacionalizados en conformidad al del artículo 10, tendrán opción a cargos públicos de elección popular sólo después de cinco años de estar en posesión de sus cartas de nacionalización.

\section{Capítulo III}

DE LOS DERECHOS Y DEBERES CONSTITUCIONALES

Artículo 19.- La Constitución asegura a todas las personas:

$1^{\circ}$. El derecho a la vida y a la integridad física y psíquica de la persona.

$2^{\circ}$. La igualdad ante la ley. En Chile no hay persona ni grupo privilegiados. En Chile no hay esclavos y el que pise su territorio queda libre. Hombres y mujeres son iguales ante la ley.

Ni la ley ni autoridad alguna podrán establecer diferencias arbitrarias. 
$16^{\circ}$. La libertad de trabajo y su protección.

Toda persona tiene derecho a la libre contratación y a la libre elección del trabajo con una justa retribución.

Se prohíbe cualquiera discriminación que no se base en la capacidad o idoneidad personal, sin perjuicio de que la ley pueda exigir la nacionalidad chilena o límites de edad para determinados casos.

Como vemos, la referencia inicial en términos de derechos recae sobre la persona y su condición de libres e iguales en dignidad y derechos. Es en este sentido una exigencia formal al principio de igual característico del ideal democrático, quizá el único que ha sobrevivido como principio activo, pero no siempre garantizado, dentro de las estructuras políticas de las democracias liberales.

Pero el discurso sobre los derechos de la persona queda inmediatamente neutralizado cuando se condiciona de forma indirecta la protección de los mismos solo a los integrantes de la comunidad nacional. Por tanto, lo que en espíritu se enuncia como derechos de la persona, fundamentalmente los civiles y los sociales, pasan a ser interpretados como derechos de los nacionales. Tal condicionamiento muestra uno de los retos que supone para la migración internacional el reconocimiento de la universalidad de los derechos fundamentales. La pertenencia a una comunidad política no puede sostenerse desde el principio de la nacionalidad, al menos desde una perspectiva de pluralismo democrático.

En esta misma línea, el texto constitucional señala que, en el caso de los extranjeros, no podrán ejercer los derechos de ciudadanía, tradicionalmente concebidos como derechos políticos, hasta cumplidos los cinco años de residencia en el país. Además, se añade que incluso habiendo adquirido la nacionalidad, los extranjeros nacionalizados no podrán ejercer el sufragio pasivo hasta los cinco años posteriores a la obtención de tal condición. Ante este escenario, las garantías constitucionales se verán complementadas con la jurisprudencia que emane de los tratados internacionales en vigor ratificados por el Estado chileno. Ese parece ser uno de los marcos de referencia a tener en cuenta para el diseño de una política de gestión de la inmigración ante la falta de presencia de este tema en el texto constitucional.

Una mirada general de la normativa vigente en materia de migración entrega luces sobre el escaso reflejo que la misma proyecta en términos de derechos fundamentales.Como podemos apreciar en la Tabla $\mathrm{N}^{\circ} 1$, predomina una concepción de gestión administrativa de la migración desconectada de la dimensión de derechos necesaria para asumir el fenómeno en su complejidad en tanto nuevos miembros de la comunidad política. 
Tabla Nº1: Normativa sobre migración y derechos fundamentales.

\begin{tabular}{|c|c|c|c|}
\hline Normativa & Función & $\begin{array}{c}\text { Aspectos } \\
\text { relevantes }\end{array}$ & $\begin{array}{c}\text { Derechos } \\
\text { fundamentales }\end{array}$ \\
\hline $\begin{array}{l}\text { Decreto Ley } \\
\text { N }^{0} 1.094 \\
\text { de } 1975 .\end{array}$ & $\begin{array}{l}\text { Establece normas } \\
\text { sobre extranjeros en } \\
\text { Chile. }\end{array}$ & $\begin{array}{l}\text { Artículo 15.- Se } \\
\text { prohíbe el ingreso al } \\
\text { país de los siguientes } \\
\text { extranjeros: } \\
\text { 1.- Los que propaguen } \\
\text { o fomenten de palabra } \\
\text { o por escrito o por cual- } \\
\text { quier otro medio, doc- } \\
\text { trinas que tiendan a des- } \\
\text { truir o alterar por la } \\
\text { violencia, el orden so- } \\
\text { cial del país o su siste- } \\
\text { ma de gobierno, los que } \\
\text { estén sindicados o ten- } \\
\text { gan reputación de ser } \\
\text { agitadores o activistas } \\
\text { de tales doctrinas y, en } \\
\text { general, los que ejecu- } \\
\text { ten hechos que las leyes } \\
\text { chilenas califiquen de de- } \\
\text { lito contra la seguridad } \\
\text { exterior, la soberanía } \\
\text { nacional, la seguridad in- } \\
\text { terior o el orden público } \\
\text { del país y los que reali- } \\
\text { cen actos contrarios a } \\
\text { los intereses de Chile o } \\
\text { constituyan un peligro } \\
\text { para el Estado. }\end{array}$ & $\begin{array}{l}\text { Ninguna referen- } \\
\text { cia a derechos } \\
\text { fundamentales } \\
\text { La ley al estable- } \\
\text { cer que el Minis- } \\
\text { terio del Interior } \\
\text { y Seguridad Públi- } \\
\text { ca enfoca la inmi- } \\
\text { gración como } \\
\text { problema de segu- } \\
\text { ridad nacional. }\end{array}$ \\
\hline $\begin{array}{l}\text { Decreto } \\
\text { Supremo } \\
N^{\circ} 597 \\
\text { de } 1984 .\end{array}$ & $\begin{array}{l}\text { Reglamentar el DL. } \\
1.094\end{array}$ & $\begin{array}{l}\text { Criterios administrati- } \\
\text { vos y procedimentales } \\
\text { para ejecutar el DL. } \\
1.094\end{array}$ & $\begin{array}{l}\text { Ausencia de enfo- } \\
\text { que de Derechos. }\end{array}$ \\
\hline $\begin{array}{l}\text { Decreto } \\
\text { Supremo } \\
\mathrm{N}^{\circ} 680 \\
\text { de } 1990 .\end{array}$ & $\begin{array}{l}\text { Crea Oficina de In- } \\
\text { formación, Recla- } \\
\text { mos y Sugerencias. }\end{array}$ & $\begin{array}{l}\text { Departamento de Ex- } \\
\text { tranjería y Migraciones } \\
\text { desarrollo modificacio- } \\
\text { nes para mejorar la } \\
\text { atención de sus servicios, } \\
\text { dentro de los cuales se } \\
\text { encontró: la solicitud } \\
\text { por correo de la residen- } \\
\text { cia sujeta a contrato de } \\
\text { trabajo, y la creación de } \\
\text { una Oficina de Informa- } \\
\text { ción, Reclamos y Suge- } \\
\text { rencias (OIRS) }\end{array}$ & $\begin{array}{l}\text { Aborda el tema } \\
\text { migratorio en } \\
\text { cuanto estructura } \\
\text { administrativa. }\end{array}$ \\
\hline
\end{tabular}




\begin{tabular}{|c|c|c|c|}
\hline $\begin{array}{l}\text { Decreto Ley } \\
\text { N }^{\text {o }} 19.880 \\
\text { de } 2003 .\end{array}$ & $\begin{array}{l}\text { Ley de Bases de } \\
\text { Procedimiento Ad- } \\
\text { ministrativo }\end{array}$ & $\begin{array}{l}\text { Establece las bases de } \\
\text { los procedimientos ad- } \\
\text { ministrativos que rigen } \\
\text { los actos de los órga- } \\
\text { nos de la administra- } \\
\text { ción del Estado. }\end{array}$ & $\begin{array}{l}\text { Aborda el tema } \\
\text { migratorio en } \\
\text { cuanto estructura } \\
\text { administrativa. }\end{array}$ \\
\hline $\begin{array}{l}\text { Instructivo } \\
\text { Presiden - } \\
\text { cial } N^{\circ} 009 \\
2008\end{array}$ & $\begin{array}{l}\text { Impartir Instruccio- } \\
\text { nes sobre la Políti- } \\
\text { ca Nacional Migra- } \\
\text { toria }\end{array}$ & $\begin{array}{l}\text { Se presenta Chile como } \\
\text { país de acogida; Inte- } \\
\text { gración de los } \\
\text { inmigrantes; Trata- } \\
\text { miento internacional } \\
\text { de la temática migra- } \\
\text { toria; y Capacidad de } \\
\text { regulación y administra- } \\
\text { ción. } \\
\text { No se concretó en la } \\
\text { práctica. }\end{array}$ & $\begin{array}{l}\text { Declaración de } \\
\text { principios de ape- } \\
\text { go al marco de los } \\
\text { tratados interna- } \\
\text { cionales ratifica- } \\
\text { do por Chile. }\end{array}$ \\
\hline $\begin{array}{l}\text { Decreto } \\
1393 \\
\text { de } 2014 .\end{array}$ & $\begin{array}{l}\text { Crea la comisión } \\
\text { asesora del Presi- } \\
\text { dente de la Repúbli- } \\
\text { ca denominada } \\
\text { "Consejo de Políti- } \\
\text { ca Migratoria”, de } \\
\text { carácter permanen- } \\
\text { te, que tendrá como } \\
\text { objetivo elaborar la } \\
\text { Política Nacional } \\
\text { Migratoria y coor- } \\
\text { dinar las acciones, } \\
\text { planes y programas } \\
\text { de los distintos ac- } \\
\text { tores institucionales } \\
\text { en materia migra- } \\
\text { toria. }\end{array}$ & $\begin{array}{l}\text { Dispone que se requie- } \\
\text { re un tratamiento inter- } \\
\text { sectorial que permita } \\
\text { una atención multidis- } \\
\text { ciplinaria a los desafíos } \\
\text { que impone un fenó- } \\
\text { meno tan complejo } \\
\text { como el de las migra- } \\
\text { ciones internacionales }\end{array}$ & $\begin{array}{l}\text { Declaración de } \\
\text { principios de ape- } \\
\text { go a al marco de } \\
\text { los tratados in- } \\
\text { ternacionales ra- } \\
\text { tificado por Chi- } \\
\text { le }\end{array}$ \\
\hline
\end{tabular}

Fuente: Elaboración propia

Como se indica en el Instructivo Presidencial No 009 de 2008, que constituye la plataforma político-jurídica del Decreto 1393 de 2014, la base normativa de la política migratoria chilena emanará de los convenios internacionales firmados por el Estado chileno. Esta consideración da la medida del nivel de desconexión entre el marco normativo chileno sobre migración y los efectos deseados una vez firmados los instrumentos internacionales respectivos. La TablaN ${ }^{\circ} 2$ brinda una muestra de los reducidos efectos que tales instrumentos han tenido en la normativa de migración. 
Polis, Revista Latinoamericana, Volumen 14, No 42, 2015

Tabla N²: Principales instrumentos de Naciones Unidas sobre Derechos Humanos y otras materias vinculadas a la migración internacional ratificados por el Estado chileno.

\begin{tabular}{|c|c|c|c|}
\hline Instrumento & Firma & Ratificación & $\begin{array}{l}\text { Efectos en la nor- } \\
\text { mativa migratoria }\end{array}$ \\
\hline $\begin{array}{l}\text { Convención internacional } \\
\text { para la eliminación de todas } \\
\text { las formas de discriminación } \\
\text { racial. }\end{array}$ & 03/10/1966 & $20 / 10 / 1971$ & \\
\hline $\begin{array}{l}\text { Pacto Internacional de De- } \\
\text { rechos Económicos, Socia- } \\
\text { les y Culturales. }\end{array}$ & $16 / 09 / 1969$ & $10 / 02 / 1972$ & \\
\hline $\begin{array}{l}\text { Pacto Internacional de De- } \\
\text { rechos Civiles y Políticos. }\end{array}$ & 16/09/1969 & $10 / 02 / 1972$ & \\
\hline $\begin{array}{l}\text { Convención sobre el estatu- } \\
\text { to de los refugiados. }\end{array}$ & 28/01/1972 & $\begin{array}{l}\text { (En vigor sin } \\
\text { necesidad de } \\
\text { ratificación) }\end{array}$ & \\
\hline $\begin{array}{l}\text { Protocolo facultativo de la } \\
\text { Convención sobre el estatu- } \\
\text { to de los refugiados. }\end{array}$ & 27/04/1972 & $\begin{array}{l}\text { (En vigor sin } \\
\text { necesidad de } \\
\text { ratificación) }\end{array}$ & $\begin{array}{l}\text { Ley } 20.430 \text { de } 2010 . \\
\text { Establece disposi- } \\
\text { ciones sobre pro- } \\
\text { tección de refugia- } \\
\text { dos. }\end{array}$ \\
\hline $\begin{array}{l}\text { Convención contra la elimi- } \\
\text { nación de todas las formas } \\
\text { de discriminación contra la } \\
\text { mujer (CEDAW) }\end{array}$ & $17 / 07 / 1980$ & 07/12/1989 & \\
\hline $\begin{array}{l}\text { Convención contra la tor- } \\
\text { tura y otros tratos o penas } \\
\text { crueles, inhumanos o degra- } \\
\text { dantes. }\end{array}$ & 23/09/1987 & $30 / 09 / 1988$ & \\
\hline $\begin{array}{l}\text { Convención sobre los dere- } \\
\text { chos del niño. }\end{array}$ & 26/01/1990 & 13/08/1990 & \\
\hline $\begin{array}{l}\text { Convención internacional } \\
\text { sobre la protección de los } \\
\text { derechos de todos los traba- } \\
\text { jadores migratorios y de sus } \\
\text { familiares. }\end{array}$ & 24/09/1993 & $21 / 03 / 2005$ & \\
\hline $\begin{array}{l}\text { Convención sobre los dere- } \\
\text { chos del niño relativo a la } \\
\text { venta de niños, la prostitu- } \\
\text { ción infantil y la utilización } \\
\text { de niños en la pornografía. }\end{array}$ & $23 / 06 / 2000$ & $06 / 02 / 2003$ & \\
\hline
\end{tabular}




\begin{tabular}{|l|l|l|l|}
\hline $\begin{array}{l}\text { Convención internacional } \\
\text { contra la delincuencia orga- } \\
\text { nizada transnacional. }\end{array}$ & $13 / 12 / 2000$ & $29 / 11 / 2004$ & \\
\hline $\begin{array}{l}\text { Protocolo Facultativo de la } \\
\text { Convención sobre los dere- } \\
\text { chos del niño relativo al } \\
\text { involucramiento de niños en } \\
\text { conflictos armados. }\end{array}$ & $05 / 11 / 2001$ & $31 / 07 / 2003$ & \\
$\begin{array}{l}\text { Protocolo contra la trata de } \\
\text { migrantes por tierra, mar y } \\
\text { aire. }\end{array}$ & $08 / 08 / 2002$ & $29 / 11 / 2004$ & $\begin{array}{l}\text { Ley 20.507 de } \\
\text { 2011. Tipifica los } \\
\text { delitos de tráfico ilí- } \\
\text { cito de migrantes y } \\
\text { trata de personas y } \\
\text { establece normas } \\
\text { para su prevención } \\
\text { más efectiva per- } \\
\text { secución criminal. }\end{array}$ \\
\hline $\begin{array}{l}\text { Protocolo para prevenir, } \\
\text { reprimir sancionar la trata } \\
\text { de personas, especialmente } \\
\text { mujeres y niños. }\end{array}$ & $08 / 08 / 2002$ & $29 / 11 / 2004$ & \\
\hline $\begin{array}{l}\text { Protocolo facultativo a la } \\
\text { tura y otros contra la tor- } \\
\text { crueles, inhumanos o degra- } \\
\text { dantes. }\end{array}$ & $06 / 06 / 2005$ & $12 / 12 / 2008$ & \\
\hline
\end{tabular}

Fuente: Elaboración propia a partir de United Nations, Treaty Collection: http:// treaties.un.org y http://www.leychile.cl/

Es necesario aclarar que en la Tabla $\mathrm{N}^{\circ} 2$ nos referimos específicamente a los efectos en normativa migratoria y no a la repercusión en el marco normativo general del Estado. Se trata de aquellos efectos que permiten concebir y abordar la realidad migratoria de Chile desde sus necesidades de reconocimiento en términos de derechos.

En este sentido es preciso señalar que Chile no ha ratificado ninguno de los principales instrumentos de la Organización Internacional del Trabajo (OIT) relacionados de manera directa con el trabajo migrante. Como se muestra en la Tabla $\mathrm{N}^{\circ} 3$, no hay efectos prácticos que evidencien un avance coherente entre los instrumentos internacionales creados al efecto y la gestión de la migración. 


\section{Tabla N³: Instrumentos de la OIT sobre la materia no ratificados por el Estado chileno.}

\begin{tabular}{|l|l|}
\hline Convenio $\mathrm{N}^{\circ} \mathbf{9 7}$ & Sobre trabajadores migrantes, 1949, (actualizado). \\
\hline Recomendación $\mathrm{N}^{\circ} \mathbf{8 6}$ & $\begin{array}{l}\text { Sobre trabajadores migrantes, 1949, (actualizado). No tiene carácter } \\
\text { vinculante. }\end{array}$ \\
\hline Convenio $\mathrm{N}^{\circ} \mathbf{1 4 3}$ & Disposiciones complementarias sobre trabajadores migrantes, 1975. \\
\hline Recomendación $\mathrm{N}^{\circ} \mathbf{1 5 1}$ & Sobre trabajadores migrantes, 1975. No tiene carácter vinculante. \\
\hline
\end{tabular}

Fuente: Elaboración propia.

La revisión de la normativa vigente sobre migración en Chile deja en evidencia una escasa adecuación con respecto a los instrumentos internacionales recogidos en la tabla $\mathrm{n}^{\circ}$ 02, los cuales solo han influido en la adaptación de la legislación nacional en los temas relativos a trata, tráfico y refugiados. En tal sentido, la referencia realizada en el cuerpo normativo y en la Constitución Política de la República sobre el cumplimiento de los tratados internacionales queda en papel mojado debido a la tenue influencia que los mismos han tenido en la normativa nacional.

Finalmente, el 4 junio de 2014 ingresó al parlamento por mensaje del presidente el proyecto de Ley de inmigración y extranjería cuyo objetivo es sustituir la anticuada ley de 1975. Los retos que debería asumir la nueva Ley son innumerables ante la ausencia en la actualidad de una política de gestión democrática de la inmigración.

\section{Las políticas de gestión de la diversidad cultural y el paradigma de gestión democrática de la diversidad cultural}

Como ha subrayado Benhabib (2002), ya no podemos seguir sosteniendo esa suerte de «universalismo de sustitución» que permite al mismo tiempo presentarnos como defensores de los derechos humanos y negarlos a quien no es persona porque no devuelve nuestra imagen en el espejo: la de varón, mayor de edad, occidental, autosuficiente o al menos trabajador, heterosexual, etc. Imagen a la que no responden las mujeres, los niños, los nacidos fuera del ámbito de opulencia del Norte, los que se identifican con tradiciones culturales ajenas a la occidental, los que no tienen trabajo o sólo lo obtienen en el mercado informal o clandestino o trabajan en el orden privado (en la casa), los que sostienen otras opciones sexuales.

La hegemonía de un paradigma como el asimilacionista aún pervive en el contexto político y normativo chileno. Si bien no podría decirse que existen políticas abiertamente excluyentes, lo cierto es que la ausencia de políticas proactivas, que abran el camino al pluralismo cultural es notoria. Suele ser una práctica habitual el hecho de que las instituciones asuman una retórica discursiva progresista afín a los postulados del pluralismo cultural, pero que en la práctica no se produzca una modulación de la ges- 
tión de la migración acorde a tales postulados. A pesar de lo mucho que se ha avanzado en el ámbito académico y en la propia sociedad civil, donde la cuestión de la gestión democrática de la diversidad llegó para quedarse, la voluntad política para lograr un proyecto de comunidad política inclusiva es insuficiente.

Recordemos que desde el pluralismo cultural se reconfigura la percepción sobre la diversidad como algo positivo y, por tanto, parte de una idea distinta de cultura, concebida como un elemento básico desde el que todo individuo estructura su relación con el otro. En este sentido las diferencias culturales, lingüísticas, étnicas y religiosas deben ser no solo aceptadas, sino también valoradas positivamente. La permanencia de las pautas culturales propias, con apego innegociable al espíritu de los derechos humanos, así como la pertenencia igualitaria en la estructura de la sociedad, permitiría una existencia menos conflictiva y favorecería la construcción de un proyecto de convivencia en común.

Es el Estado, a fin de cuentas, quien instaura, en función de normas establecidas, cuándo se adquiere y se pierde el estatuto de ciudadanía, transformada erróneamente en expresión de la nacionalidad. En el diseño de esas normas juega un papel determinante la esencialidad cultural que se le imprima a la nación o la esencialidad nacional que se le adjudique a la cultura. De ahí la necesidad de una profundización de la democracia liberal, tradicionalmente ciega a la diferencia cultural bajo el postulado de que el Estado liberal opera de forma neutral ante ellas.

Tal neutralidad niega la legitimidad a expresiones colectivas de voluntad general distintas ala de la nación políticamente constituida. El reconocimiento de contextos referenciales particulares es vital para la convivencia mutua a partir de procesos deliberativos y no a través de la homogenización cultural bajo el patrón de la mayoría.

A partir de lo anterior no resulta difícil constatar que la actualidad de las políticas del Estado chileno sobre la gestión de la migración necesita la profundización democrática exigida por el paradigma del pluralismo cultural. Desde el punto de vista normativo dicho paradigma ha ido ganando espacio en los instrumentos del derecho internacional. Como hemos señalado, la legislación chilena no ha sido lo suficientemente receptiva a esta influencia. Se ha optado por una estrategia de cumplimiento de los convenios internacionales sobre esta materia como horizonte exclusivo, olvidando la necesidad de desarrollos internos de innovación democrática de tipo institucional, jurídico y político.

Pero incluso tal elección no se ha materializado en un desarrollo normativo coherente con el espíritu de los compromisos adquiridos a nivel internacional. Así lo reflejan las dificultades para implementar el Convenio 169 de la OIT Sobre Pueblos Indígenas y Tribales en pueblos independientes. La ratificación del Convenio no se vio precedida por un reconocimiento constitucional del carácter plurinacional, pluricultural o multicultural de la 
comunidad política. Ello evidencia la falta de conciencia de lo que un reconocimiento de esta envergadura implica.

Lo mismo sucede con la ausencia de una política de gestión de la migración internacional y el rezago de las escasas acciones que de forma sectorial y no de forma integral rigen en esta materia. Al igual que sucede con los pueblos originarios, los instrumentos internacionales sobre la materia ratificados por el Estado chileno no se han materializado de forma fehaciente en un cambio de la normativa nacional y muchos otros se encuentran a la espera de ser ratificados. Prevalece una mirada del migrante desde una variable puramente económica, como fuerza de trabajo, y no en términos de derechos fundamentales.

En este sentido, en el caso chileno no encontramos elementos de coherencia entre las políticas actuales de gestión de la diversidad y el paradigma del pluralismo cultural. Podríamos hablar de la prevalencia de un paradigma asimilacionista en transición. Solo las acciones futuras entregaran elementos sobre las velocidades de dicho proceso, que en todo caso debería orientarse desde una real profundización dinámica de la democracia que muestre valor para reconocer el contexto multicultural sobre el cual se constituye operando una reinterpretación de su construcción política y de los derechos humanos en clave multicultural.

\section{Conclusiones}

Las propuestas políticas de gestión de la diversidad cultural no deben ser entendidas por sí solas como un intento de profundización democrática. Es el reconocimiento explícito del ejercicio de los derechos humanos de todos los individuos, independientemente de su identificación religiosa, étnica, lingüística, de género o nacionalidad, la antesala ineludible para tal finalidad. La misma debe materializarse en un modelo de gestión, o de lo contrario solo sería una retórica más. La voluntad política de gestionar la diversidad cultural no ha sido siempre canalizada, ese es precisamente el reto, a través de principios democráticos e inclusivos como marco de orientación de las prácticas políticas.

El asimilacionismo constituye un marco general de comprensión de la diversidad cultural, de cuya cosmovisión se han derivado aplicaciones modélicas como el anglo-conformity y el melting pot. Sus características de connotación moral, política, jurídica y social nos indican la intencionalidad de la gestión, al mismo tiempo que nos permiten identificar el qué, el cómo y el porqué de la finalidad de la gestión de la diversidad.

El paradigma del pluralismo cultural plantea la necesidad impostergable de replantearse las categorías políticas tradicionales del Estado identitario. Realiza una crítica profunda a la concepción de comunidad política basada en la inclusión a partir de la pérdida de los marcos culturales de referencia que difieran de la cultura mayoritaria y/o hegemónica. De ahí 
que las modulaciones teórico-políticas que emanan de este paradigma, el multiculturalismo y el interculturalismo, demandan una lectura multicultural no solo de los derechos humanos y los criterios de pertenencia a la comunidad política, sino también de la democracia obcecada en los marcos del procedimentalismo y el universalismo igualitario.

En el caso de Chile, no encontramos de forma explícita un modelo articulado de gestión de la diversidad cultural. Incluso, si intentáramos encontrar el sentido quepor omisión desvela el marco normativo existente, no cabe duda de que el mismo se encuentra muy cercano al paradigma asimilacionista. No hemos encontrado elementos que permitan confirmar la existencia de políticas afines a las orientaciones del pluralismo cultural. Solo hemos podido identificar un intento (Decreto 1393 de 2014) que, a modo de declaración de principios, podría allanar el camino para el desarrollo de iniciativas innovadoras relativas a la gestión democrática de la migración. Pero lo cierto es que a día de hoy tal intento no ha logrado traducirse en un modelo de gestión de la migración.

El diseño de un modelo de gestión democrática de la migración no apunta exclusivamente una política focalizada. En términos de derechos fundamentales, la gestión democrática de la migración desborda sus límites apuntando a una concepción plural de la comunidad política poniendo en crisis la relación tradicional entre democracia y ciudadanía, sobre todo a partir de una lectura multicultural de la misma. Este es un reto para la sociedad chilena en su conjunto. 
Polis, Revista Latinoamericana, Volumen 14, $N^{\circ}$ 42, 2015

\section{Notas}

${ }^{1}$ Este trabajo es uno de los resultados del Proyecto Posdoctoral financiado por el Consejo Nacional de Ciencia y Tecnología de Chile (CONICYT): La gestión de la diversidad cultural en Chile. El tiempo de los derechos. Programa PAI: proyecto_82130026.

${ }^{2}$ El modelo anglo-conformity sirvió de marco de referencia para políticas de segregación racial instrumentadas a partir de estrategias educativas discriminatorias o la propia separación de los espacios públicos diseccionados en sitios para negros y para blancos.

${ }^{3}$ Es necesario apuntar que a diferencia de la anglo-conformity, este modelo no alcanzó un nivel relativamente elaborado de sistematización o desarrollo doctrinal, por lo que puede ser considerado como una expresión verosímil del mito nacional estadounidense del mestizaje de las razas o culturas.

${ }^{4}$ Estos nos hace recordar las reflexiones de Wright (1999), uno de los neomarxistas estadounidenses más influyentes de las últimas décadas, relativas a introducir en los análisis sociales categorías de bajo nivel de abstracción al estilo weberiano, frente al conocido modelo marxista donde una teoría fundamental regula de forma inflexible la realidad que intenta describir.

${ }^{5}$ Referida, esencialmente, al multiculturalismo radical: aquella concepción que niega el intercambio entre grupos culturales, como si fuesen especies de culturas incontaminadas.

${ }^{6}$ Según Zapata Barrero (2008: 178) la economía de los discursos se interesa por cómo se regula socialmente la producción discursiva, por cómo se establecen normas y restricciones que los discursos deben cumplir en los distintos contextos, cómo se bloquea o, al menos, obstaculizaelacceso a aquellos discursos que no satisfacen estas regulaciones: cómo se ejerce y en qué consiste la «apropiación del discurso», por medio de la cual algunos grupos sociales e instituciones que tienen acceso a los medias de producción del discurso establecen normas de producción y circulación, mientras que otros resultan desposeídos de la palabra. 


\section{Bibliografía}

Bajo, N. (2007), “Conceptos y teorías sobre la inmigración”, Anuario jurídico y económico escurialense, XL, pp. 817-840.

Benhabib, S. (2002), The claims of Culture,Princeton U. Press, Princeton.

Cano, V., y Soffia, M. (2009), “Los estudios sobre migración internacional en Chile: apuntes y comentarios para una agenda de investigación actualizada”,Papeles de Población, vol. 15, n 61, pp. 129-167. Recuperado el 3 de febrero de 2014 de http://www.scielo.org.mx/pdf/pp/v15n61/v15n61a7.pdf

Colom, F. (1998), Razones de identidad. Pluralismo cultural e integración política, Anthropos, Barcelona.

De Lucas, J. (2009), “Inmigración, diversidad cultural, reconocimiento político”, Papers n 94, pp.11-27.

Depolo, S., y Henríquez, G. (2006), “Emigración y exclusión social en el mercado laboral chileno”, Sociedad Hoy, n 10, pp. 109-126. Recuperado el 23 de diciembre de 2013, de http://www.redalyc.org/articulo.oa?id=90201007

Etxeberria, X. (2004), Sociedades multiculturales, Mensajero, Bilbao.

Ferrajoli, L. (2007), "Universalismo de los derechos fundamentales y multiculturalismo”, Revista Internacional de Filosofía Política, n 30, pp. 57-64.

Ídem (2004), Derechos y garantías: la ley del más débil, Trotta, Madrid.

Giménez, C. (2003), “Pluralismo, Multiculturalismo e Interculturalidad. Propuesta de clarificación y apuntes educativos”, Revista Educación y Futuro, $\mathrm{n}^{\circ} 8$, pp. 11-20.

Herver, W. (1964), Católicos, protestantes y judíos, Libreros mexicanos unidos, Ciudad de México.

Jimenez, R., y Huatay, C. (2005), Algo está cambiando: globalización, migración y ciudadanía en las asociaciones de peruanos en Chile, Gotelli, Santiago de Chile.

Kuhn, T. (1971), La estructura de las revoluciones científicas, Fondo de Cultura Económica, Ciudad de México.

Lamo, E., y LLOBERA, J. (1995), Culturas, estados, ciudadanos: una aproximación al multiculturalismo en Europa, Alianza, Madrid.

Lopez Sala, A. (2002), “Los retos políticos de la inmigración”, Revista Isegoría, $\mathrm{n}^{\circ}$ 26, pp. 85-105. 
Malgesini, G., y Gimenez, M. (2000), Guía de conceptos sobre migraciones, racismo e interculturalismo, Cataratas, Madrid.

Pena J. (2000), La ciudadanía hoy: problemas y propuestas, Universidad de Valladolid, Secretariado de publicaciones e intercambio editorial, Valladolid.

Pérez De La Fuente, O. (ed.) (2008), Una discusión sobre la gestión de la diversidad cultural, Madrid.

Ritzer, G. (1993), Teoría sociológica contemporánea, McGRAW-HILL, Madrid.

Ruiz Vieytez, E. (2006), Minorías, inmigración y democracia en Europa. Una lectura multicultural de los derechos humanos, Tirant lo Blanch, Valencia.

Schiappacasse, P. (2008), “Segregación residencial y nichos étnicos de los inmigrantes internacionales en el área Metropolitana de Santiago”, Revista de Geografía Norte Grande, ${ }^{\circ}$ 29, pp. 21-38. Recuperado el 23 de enero de 2014, de http://www.scielo.cl/pdf/rgeong/n39/art03.pdf

Stefoni, C. (2011a), Perfil migratorio de Chile, Organización Internacional para la Migraciones, Buenos Aires. Recuperado el 20 de junio de 2014, de http://desarrollo.sociologia.uahurtado.cl/wp-content/uploads/2014/04/perfil-Chile-versi\%C3\%B3n-final.pdf

Ídem (2011b), “Ley y política migratoria en Chile. La ambivalencia en la comprensión del migrante”,en B. Feldman, L. Rivera, C. Stefoni y M. I. Martínez (coords.), La construcción social del sujeto migrante en América Latina prácticas, representaciones y categorías, FLACSO, Quito, pp. 79-110.

Torres, F. (2005), “De la asimilación al pluralismo. Inmigración y gestión de la diversidad cultural en las sociedades contemporáneas”, Revista Arxius de Ciències Socials, n ${ }^{0}$ 11, pp. 61-87.

Velazco, J. (2006), “Mutaciones de la ciudadanía en el contexto de las migraciones transnacionales”, Cuadernos Electrónicos de Filosofía del Derecho, 14. Recuperado el 18 enero de 2009, de http://www.uv.es/CEFD/14/ velasco.pdf

Zapata Barrero, R. (2001), Ciudadanía, democracia y pluralismo cultural, Arthropos, Barcelona. 